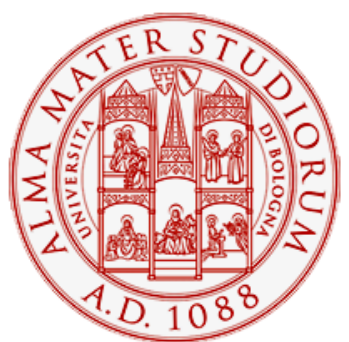

Alma Mater Studiorum - Università di Bologna DEPARTMENT OF ECONOMICS

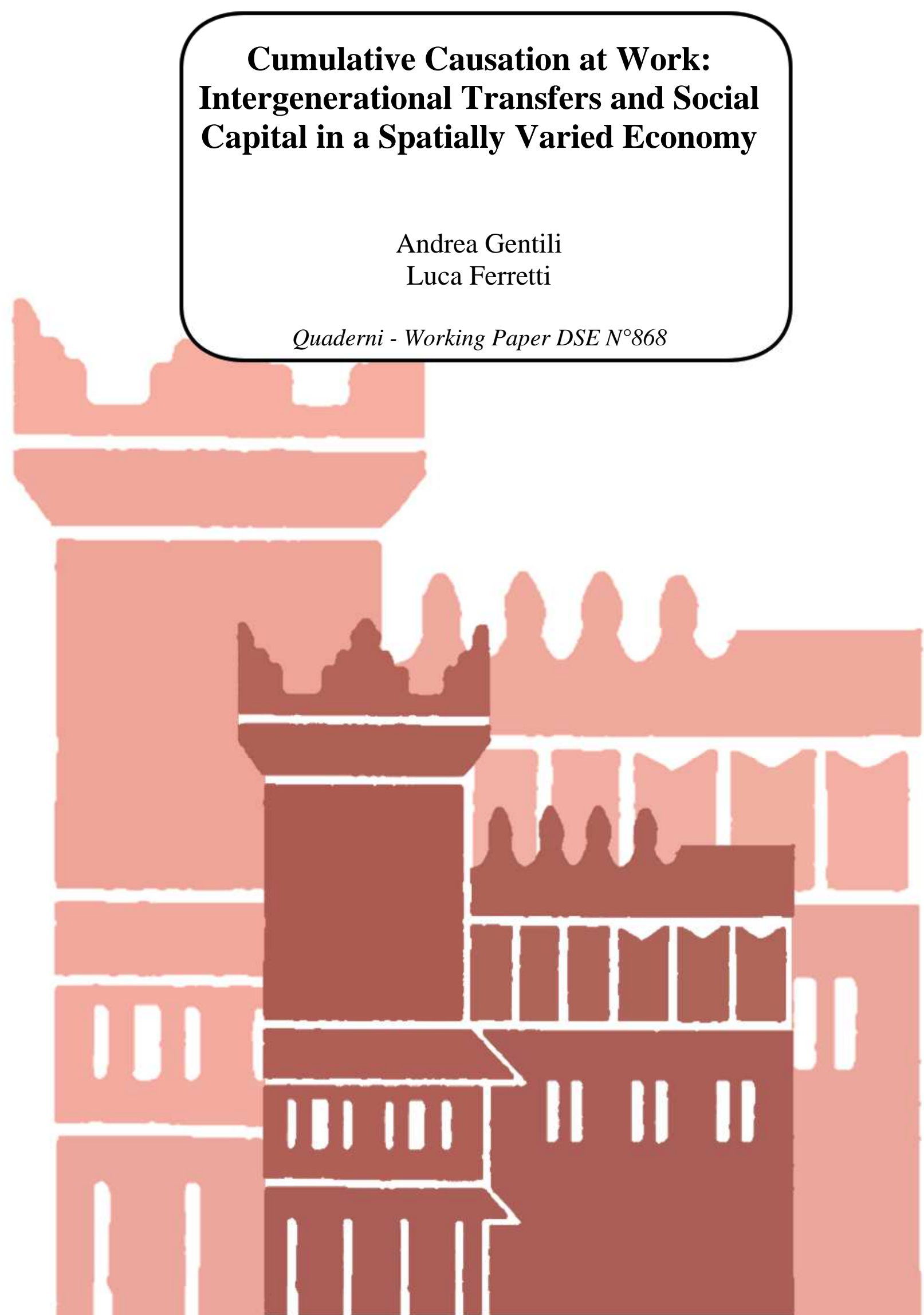




\section{Cumulative Causation at Work: Intergenerational Transfers and Social Capital in a Spatially Varied Economy}

Andrea Gentili ${ }^{1}$

Luca Ferretti ${ }^{2}$

\section{Abstract}

This paper models the dynamic of migration with a particular focus on the cumulative process that causes a variation in the distribution of income in sending communities and therefore a variation in the distribution of skills across different cohorts. The model provides a theoretical framework to Cumulative Causation theory of migration and specifically a theoretical rationale behind the use of migration prevalence ratio to study migration flows. Moreover the model shows how brain drain (in sending communities) and negative cohort effect in terms of education (in receiving communities) are the result of a positive selection of migrants in terms of skills if there is a intergenerational transmission of education.

Keywords: Migration, Overlapping Generation, Networks, Selection

\footnotetext{
${ }^{1}$ Department of Economics (DSE), Alma Mater Studiorum - University of Bologna

${ }^{2}$ CRAG (CSIC-UAB-IRTA-UB), Campus Universitat Autònoma de Barcelona, 08193 Bellaterra, Spain
} 


\section{Introduction}

International migration is one of the most debated issues among scholars, policy makers and public opinion. Cumulative Causation theory as developed by Massey and followers is one of the most extensive and comprehensive theory of migration and it is largely accepted among scholars, however it lacks of a formal structure. This paper is aimed to fill this gap. We propose a possible formalization of Cumulative Causation based on an overlapping generation model as the one proposed in Loury (1981). Our approach provides a formal background to the use of Migration Prevalence ratios as proposed in Massey et al. (1994) and provides a possible interpretation to the selection of migrants phenomenon.

As argued in Durand et al. (2001) migration prevalence (generally used to incorporate the community-level migration network) does not describe the migration flow per se, but rather, a phase in its development. It is a useful measure which can capture the level of development of migration flows in a community. ${ }^{3}$ Each migrant, creating new links in the receiving country and retaining ${ }^{4}$ some in the sending country, modifies the social environment in both, allowing the accumulation of migration-specific knowledge (migration social capital) able to reduce the costs and risks of migration and generating a self-perpetuating mechanism. In particular, networks affect the relation between migration and wealth, mitigating the effect of budget constraints not only by reducing costs and risks, but also acting as substitutes for financial and insurance markets. ${ }^{5}$

The endogenous process identified by network theory is not limited to potential migrants, since migration alters the whole sending country's socio-economic environment as proposed in Cumulative Causation theory. The accumulation of migration-specific social capital, remittances, changes in the distribution of wealth ${ }^{6}$ and land, all concur in generating a new set-up which has the potential to produce favorable new conditions for migration.

One of the most debated effect of this cumulative process is the "decline" in quality of migrants over time (Borjas, 1985). Literature on the selection of migrants is extensive, going back

\footnotetext{
${ }^{3}$ Migration prevalence ratios are calculated with information on the date of birth of household members and on the year of their first trip to the U.S. For a complete explanation on how to compute migration prevalence ratios, see Massey et al. (1994).

${ }^{4}$ Hanson and Spilimbergo (1999) find that the purchasing power of both the U.S. and Mexico matters in border apprehension, suggesting that potential illegal migrants expect to retain connections in both countries.

${ }^{5}$ Yang (2008).

${ }^{6}$ Docquier and Rapoport (2003) develop a model to analyze the link between migration, remittances and inequality. The main pro of their model is to take into account the effect of migration in local labor markets, making migration an endogenous process even in the absence of networks able to reduce the cost of migration.
} 
to the 1978 pioneer work by Chiswick and Borjas' 1985 reply. Several prominent scholars have contributed to the debate between positive and negative selection, producing theoretical and empirical evidence to support one or the other side. It is not uncommon to read articles which, using the same or very "similar" databases, reach opposite empirical results. Recently, McKenzie and Rapoport (2007) gave a partial explanation of this phenomenon stressing the effect of networks on the composition of migration flows.

This paper proposes a theoretical framework, capable of explaining, under a few simple assumptions, this dynamic process and how positive selection and negative cohort effect are complementary in this cumulative process. In the model proposed, networks are not at the origin of the decline in the quality of migrants, but they can amplify this mechanism and the use of migration prevalence as network variable have to capture this effect.

According to Chiswick (1999), self-selection is driven by the rate of return to migration, more capable subjects being favorably selected in terms of education. If the cost of migration is too high and financial market is underdeveloped, migration is too costly for less qualified potential migrants (Zimmerman and Carter, 2003). Once migrant networks expand, lowering costs, they can allow newcomers with lower financial capabilities. With this structure of costs, we can explain the results of McKenzie and Rapoport (2007a, 2007b) in term of self-selection. Networks reducing the cost of migration allow newcomers from the left tail of the income distribution. Newcomers, being "education expensive", are more likely to have lower levels of education. The expansion of networks, at least in the medium term, causes a decrease in the quality level of migrants in terms of observable characteristics.

The model presented in this paper demonstrates that migration is a cumulative process in which each migrant alters the "structure of the world". In this framework, the dimension of flows of migrants, their level of selection in terms of observable characteristics (i.e. negative cohort effect in term of education) and the quality levels of those who are left behind (brain drain) are characterized by the moment at which migration is observed.

Through the model, we show that even in cases of extreme positive selection at individual and aggregate levels, the negative cohort effect (i.e., lower level of observable qualities of successive migration cohorts) and brain drain represent the normal evolution of migration flows when there is no economic convergence between sending and receiving countries or requalification policies. 
Although all these effects are independent of networks, once migrant networks are taken into account new effects arise. In particular networks can drastically modify what we call the natural limit of migration and the timing of migration.

\section{Basic Model}

Let us imagine an economy composed of a large number of households $j=1, \ldots, N$, with $N$ large, and overlapping generations along the lines of Samuelson (1958), in a framework similar to that of Loury (1981). ${ }^{7}$ Time is a discrete variable and each individual lives $2+1$ periods. The growth of the population is assumed at the moment to be 0 , so that in each period the same numbers of people enter and leave the economy. ${ }^{8}$

A person living in the first period is called Child, in the second Adult. Each Child is "attached" to an Adult, and this is our definition of a "strict" household. At the +1 period (third period of life) a subject is called Old and is no longer a member of the household. This is the first difference between our model and Loury's (1981): our economy is composed of two principal decision-makers, the household and what we call the "Council of Elders". The Council of Elders brings together all the Old people, and has two main functions: to provide the Old with means of survival and to make important decisions about the use of financial social capital. ${ }^{9}$ That is, the Old cannot work or produce and therefore their consumption must be financed through a "social tax" and remittances.

In our economy, the household is the basic socioeconomic unit, and the Adult makes all the economic decisions. Household income depends on the income function of the Adult, which is based on that person's level of innate abilities $(\alpha)$ and education $(e)$. As in Loury (1981), household income must be divided in each period between consumption $(c)$ and Child schooling $\left(I_{e}\right)$. In this

\footnotetext{
${ }^{7}$ We choose Loury's (1981) framework looking for a model in which innate abilities and education were taken into consideration as separate elements. Secondly, Loury's framework assumes a "balkanized" market for education - that is, households must self-finance their offspring's education. We believe it is more correct to consider education investment in developing countries, excluding the existence of working education loan markets. Even when and where free public education is available, sending children to school instead of to work is a form of investment which affects the household consumption. Last but not least, the model proposes intergeneration social mobility among households according to abilities and education levels. This implies that mobility closely depends on innate abilities and education variance, and on their payoff.

${ }^{8}$ Section 5 discusses what happens when the population grows.

${ }^{9}$ This will be discussed later on in the paper.
} 
framework, we assume no child labor ${ }^{10}$ and no savings, ${ }^{11}$ so that investment in children's education is the only way of transferring wealth across time. The education level of the household head is a function of the investment made in the previous period. Production requires neither social interaction between families nor the use of factors of production other than Adult time, which is supplied inelastically. Here is the second main difference with respect to Loury (1981): a fraction of the family income is paid to the Council of Elders' budget. Since this fraction is a fixed percentage of income, ${ }^{12}$ it does not affect either the income function form or household behavior. Households cannot decide to evade payment because the Council of Elders controls both formal and informal economies, and this means that those who evade it will suffer full punishment, which will set their productive capacity at $0 .^{13}$

Consumption is the second family activity. We do not examine here how consumption is shared within the family. The only assumption is that the utility function in terms of consumption is steep enough to ensure that consumption cannot fall, by choice, under certain survival levels.

The level of innate abilities, assigned at the beginning of life but only known when Adult age is reached, varies among individuals. Production technology is assumed to be equal for all households in each period of time. Calling income $y$ :

$$
y=f(\alpha, e)(7)
$$

is the income function of each Adult, and follows the usual assumptions, so that it is continuous, differentiable in its arguments in space $R^{+}$, increasing in its arguments and marginally decreasing.

Education is a function of investment in education $I_{e}$, and follows the same assumptions. We also assume that extreme values of abilities $(\alpha)$ have such high returns that $E[f(\alpha, e)] \gg$ $E[f(\alpha, 0)]$.

The Adult chooses how to divide income between consumption and Child education. The utility function is equal for all households and has two main arguments: actual consumption, and the discounted wellbeing of the Child when that Child becomes an Adult ${ }^{14}$. The earnings function

\footnotetext{
${ }^{10}$ Following Basu \& al. (1998).

${ }^{11}$ This is in line with the mainstream of development literature.

${ }^{12}$ It may also be interpreted as a "tax".

${ }^{13}$ See Mude \& al. (2003) page 9.

${ }^{14}$ See Becker and Tomes (1979): there are not many differences in assuming that parents care about their children's income or consumption in the future.
} 
of offspring is a random variable determined by the distribution of abilities and the education level financed by an Adult of the previous generation.

\section{2.a The Child Decision}

Before analyzing the Adult decision process, let us consider the Child decision when that Child becomes an Adult. At the beginning of their Adult life period, subjects have to decide where to settle for the rest of their lives. Here is the third main difference with respect to Loury (1981): new Adults may remain in the origin community or country or leave it for a wealthier community or country. If they stay at home, their income will be:

$$
y=f(\alpha, e)
$$

and their maximization will exactly be like that of their ancestors, so that the model can be brought back to Loury (1981). If they decide to migrate, their income will be:

$$
y_{m}=z f(\alpha, e)(9)
$$

where $z$ is the difference in real terms between the two economies. ${ }^{15}$ Migration has a cost $I_{m}$, which must be paid before it takes place. The cost incorporates both the financing of migration (housing, transport, information, etc.) as well as the psychological cost that results from leaving home and adapting to the host country:

$$
I_{m}=I_{m d}+I_{m a}
$$

where $I_{m d}$ is the fixed cost of migration and $I_{m a}$ is the psychological and adaptation component. It may also be expressed as a function of $\alpha$, to take into account the fact that more able subjects should be faster in adapting to the receiving country's context:

$$
I_{m}(\alpha)=h(\alpha)=I_{m d}+I_{m a}(\alpha)
$$

This is strictly decreasing in $\alpha$ as noted by Borjas (1999). Since there are no savings in our economy, new Adults ask the Council of Elders for the money they need. In exchange, the Council of Elders requires remittances $(R)$. However the Council of Elders cannot finance all the people who want to migrate. The rationale underlying who will be financed is discussed below.

\footnotetext{
${ }^{15}$ Here we implicitly assume that returns for abilities and education are equal across countries. What makes the difference is only the level of the economy or, as defined by Mude et al. (2003), the relative host/home infrastructure ratio.
} 
Remittances must cover at least the initial cost of migration but, as shown by Stark et al. (1989), ${ }^{16}$ they usually exceed this value:

$$
R \geq \rho\left(I_{m d}\right)
$$

where $\rho\left(I_{m}\right)$ is decided by the Council of Elders. New Adults have an incentive to migrate if:

$$
y_{m}-y \geq R+I_{m a}(\alpha)(13)
$$

We assume that free-riding is not allowed, i.e., all migrants pay remittances. This assumption is not very strict: if a person does not repay the "loan", the related Old person will be isolated and excluded from the Council: unable to work, he will die (maximum punishment). If the council decides to finance migration, the location decision of the new Adult is:

$$
\begin{aligned}
& \max \left[f(\alpha, e), z f(\alpha, e)-R-I_{m a}(\alpha)\right] \\
& \text { s.t.: } \\
& R \geq \rho\left(I_{m d}\right)
\end{aligned}
$$

If the Council decides not to finance migration, the model comes back to Loury (1981). Before proceeding to examine the Adult decision-making process, it is useful to analyze new Adults' incentives to migrate in terms of variations of innate abilities. A subject migrates if:

$$
\begin{aligned}
& y_{m}-y-R+I_{m a}(\alpha) \geq 0 \\
& (z-1) f(\alpha, e)-\rho\left(I_{m d}\right)-I_{m a}(\alpha) \geq 0
\end{aligned}
$$

The first term, $(z-1) f(\alpha, e)$, is strictly increasing in $\alpha$ and $e, \rho\left(I_{m d}\right)$ is independent of $\alpha$, and $I_{m a}(\alpha)$ is decreasing in $\alpha$, so that it enters the incentive with negative sign. Therefore, the overall equation is strictly increasing in $\alpha$. The incentive to migrate decreases if costs of migration increase. The probability that a new Adult has an incentive to migrate is:

$$
\begin{aligned}
& P\left[(z-1) f(\alpha, e)-\rho\left(I_{m d}\right)-I_{m a}(\alpha) \geq 0\right] \\
& =1-\int_{0}^{1} p_{\alpha}(\alpha) d \alpha \int_{0}^{f_{i}\left(\alpha, \frac{\rho\left(I_{m d}\right)+I_{m a}(\alpha)}{(z-1)}\right)} p_{e}(e) d e
\end{aligned}
$$

where $p_{\alpha}(\alpha)$ and $p_{e}(e)$ are the distribution of innate abilities and education respectively.

\footnotetext{
${ }^{16}$ Our economy may also be seen as an enlarged family decision.
} 


\section{2.b The Adult Decision}

Coming back to period 1, Adult, caring altruistically about family consumption and Child wellbeing, maximizes household utility:

$$
\max _{0 \leq c \leq \mathrm{y}} \mathrm{E}_{\alpha, \mathrm{p}} \mathrm{U}(c, V)
$$

where $p$ is the probability the Council finances migration, and $V$ is the indirect utility function, to take into account the wellbeing of the Child when the Child becomes an Adult. Following Loury (1981: 846) an indirect utility function is "consistent if it correctly characterizes the relationship between maximized expected utility and earnings for a parent whenever it is taken to characterize that same relationship for the offspring". In our case, $V^{*}$ is the consistent indirect utility function if it solves:

$$
\begin{aligned}
V^{*}\left(y_{1}\right)=\max _{0 \leq \mathrm{c} \leq \mathrm{y}_{1}} & {\left[\int_{0}^{\bar{\alpha}\left(\mathrm{e}\left(\mathrm{y}_{1}-\mathrm{c}\right)\right)} \mathrm{d} \alpha_{2} \mathrm{p}_{\alpha}\left(\alpha_{2}\right) \mathrm{U}\left(\mathrm{c}, \mathrm{V}^{*}\left(f\left(\alpha_{2}, \mathrm{e}\left(\mathrm{y}_{1}-\mathrm{c}\right)\right)\right)\right)\right.} \\
& +\int_{\bar{\alpha}\left(\mathrm{e}\left(\mathrm{y}_{1}-\mathrm{c}\right)\right)}^{1} \mathrm{~d} \alpha_{2} \mathrm{p}_{\alpha}\left(\alpha_{2}\right) \mathrm{U}\left(\mathrm{c}, \mathrm{V}_{\mathrm{m}}^{*}\left(\mathrm{z} f\left(\alpha_{2}, \mathrm{e}\left(\mathrm{y}_{1}-\mathrm{c}\right)-\rho\left(\mathrm{I}_{\mathrm{md}}\right)-\mathrm{I}_{\mathrm{ma}}\left(\alpha_{2}\right)\right)\right)\right]
\end{aligned}
$$

S.t.: $\bar{\alpha}\left(e\left(y_{1}-c\right)\right)$ is the level of ability, given a certain level of education, necessary for a Child to be chosen for migration by the Council, and it is identically estimated by Adult and Child, and so on for each generation. Implicitly, this means that Adult and Child will act in the same way when facing the same situation. In addition, Adults are not able to forecast correctly the distribution of ability and education for a period longer than a generation. 1 and 2 stands for the generation to which the number is related. After migration takes place, for second-generation migrants, the model comes back directly to Loury (1981).

Assumption 1: (i) $U: R_{+}^{2} \rightarrow R_{+}$is a strictly increasing, strictly concave, twice continuously differentiable function on the interior of its domain, satisfying $U(0,0)=0$. (ii) $\forall V \geq 0$,

$$
\lim _{c \downarrow 0} \frac{\partial U}{\partial c}(c, V)=+\infty
$$

(iii) There exists $\gamma>0$ such that $\forall(c, V) \in R_{+}^{2},\left(\frac{\partial U}{\partial V}\right) \in[\gamma, 1-\gamma]$

Assumption 2: (i) $f: R_{+}^{2} \rightarrow R_{+}$is continuously differentiable, strictly increasing, strictly concave in $e$, satisfying $h(0,0)=0$, and $h(0, e) \leq e, \forall e \geq 0$. 
(ii) $\frac{\partial f}{\partial \alpha}(\alpha, e) \geq \beta>0, \quad \forall(\alpha, e) \in R_{+}^{2}$

(iii) There exists $\tau>0, \hat{e}>0$ such that:

$$
e \geq \hat{e} \Rightarrow \max _{0 \leq \alpha \leq 1} \frac{\partial f}{\partial \alpha}(\alpha, e) \leq \tau<1
$$

Assumption 3: Innate economic ability is distributed on the unit interval independently and identically for all agents. Distribution has a continuous, strictly positive density function, $p_{\alpha}(\alpha):[0,1] \rightarrow R_{+}$

Theorem $1^{17}$ :Under Assumption 1 to 3, there exists a unique, consistent, indirect, utility function $V^{*}$ on $[0, y]$.

\section{Demonstration: Appendix A}

\section{2.c The Council of Elders.}

The Council of Elders is responsible for managing the community social capital through two main functions: ensuring taxes and remittance payments, and deciding whom to finance for migration. It is a structural artifact we propose to overcome the decision making process since our aim is to focus on the dynamic and not on the way each household or each community produce them. However the council could be made of one person (household head) if the migration decision is made at household level, as well as by a group of household heads (often observed in migration from rural villages in Africa) or even at country level as if migration was organized in a planned economy.

The Council can finance only a fraction of those eligible. This fraction is function of the amount of remittances the Council received in the previous period. Assuming that all the wealth controlled by the Council must be redistributed in the economy, the budget constraint of the council is:

$$
m_{t-1} R+\sum_{j=1}^{N_{t}-m_{t}} s\left(f_{j}(\alpha, e)\right)=C+m_{t} I_{m d}+I
$$

\footnotetext{
${ }^{17}$ Proof in Appendix A
} 
where $m_{t-1}$ are the number of migrants in the previous period, $R$ are remittances ${ }^{18}$, $\sum_{j=1}^{N-m} S\left(f_{j}(\alpha, e)\right)$ is the social contribution ("social tax"), $C$ is the total consumption of the Old, $m_{t} I_{m d}$ is the amount needed to finance the migration of $m$ new Adults, and $I$ is the residual part reinvested in local economy.

To simplify, we assume that the Council has an incentive to send those who have higher levels of expected returns in the receiving country. This is in line with Chiswick's (1979) selection theory, and is explained by the fact that people with higher levels of innate abilities and education have a lower probability of failure in migration. In addition, in our economy, sending people with higher incentives implies the possibility of receiving higher remittances. This is the strongest behavioral assumption in our model.

Behavioral Assumption 1: the Council of Elders finances the migration of individuals who are comparatively better in terms of the compound value of $(\alpha, e)$. That is, we assume highly positive selection of migrants in terms of a compound value of ability and education.

\section{Dynamics Analysis}

We start our analysis by considering the dimension of migration flows, and then move our focus to the quality of migrants. The strategy the Council adopts has important implications on the economic growth and convergence path among countries. Nevertheless, to determine a long-term strategy is probably beyond the Council's reach, so it will probably adopt some "rule of thumbs" or a trial-and-error process. In this context, the concept of long-term optimal strategy is unsuitable, because the optimal strategy is probably determined in the short or medium term. To be able to assess the dynamics of the model analytically, we need to assume that the Council adopts an "investment and development" strategy which that does not change in time.

Behavioral Assumption 2: the investment strategy does not change in time. The strategy is required to be constant, not optimal.

We start with a simple situation which helps to identify most of the forces involved in the dynamics. We assume that the budget of the Council of Elders is employed in constant proportions

\footnotetext{
${ }^{18}$ Here we implicitly assume that the value of the remittance does not vary across periods.
} 
between Old people's consumption and sending New Adults abroad. This implies that nothing is reinvested in the local economy:

$$
m_{t-1} R+\sum_{j=1}^{N_{t}-m_{t}} s\left(f_{j}\left(\alpha_{j}, e_{j}\right)\right)=\theta C+(1-\theta) m_{t} I_{m d}
$$

where $\theta$ is the share of the Council income used for consumption. Recalling that $R$ is a function of $I_{m d}$, the number of migrants at period $t$ is given by:

$$
m_{t}=\frac{m_{t-1} \rho\left(I_{m d}\right)}{(1-\theta) I_{m d}}+\frac{\sum_{j=1}^{N-m_{t}} s\left(f_{j}\left(\alpha_{j}, e_{j}\right)\right)-\theta C}{(1-\theta) I_{m d}}
$$

The number of migrants at time $t$ depends on the total amount of remittances in the previous period, and decreases as the cost of migration increases. Since the cost of migration is decreasing in the number of compatriots in the receiving country (Massey $\&$ al., 1994), larger $m_{t-1}$ not only increases the total amount of remittances (keeping $R$ constant) but also reduces $I_{m d}$, generating a self-perpetuating process (everything else remaining the same). At the beginning, the number of migrants which can be sent is relatively small, but increases over time through the possibility of financing more migrants each round.

It is important to note that, even when networks play no role in the migration decision, they do not influence costs or preferences, the self-perpetuating process can start. As already mentioned it is enough to keep constant the economic distance between countries $(z)$ and the proportion between Old consumption and investment in migration $(\theta)$. Each round, as $R>I_{m d}$, the Council has a return from investing in migration. With this simple framework, a growing investment in migration will be possible each round, up to the point at which everyone who has an incentive migrates. ${ }^{19}$

Two other effects must be taken into account. First, the decision on how to allocate remittances: they can only be used for consumption, and this does not generate the selfincreasing process mentioned above; otherwise they can be used to speed up migration, keeping consumption constant and sending abroad as many co-villagers as possible. Second, without population growth, $\sum_{j=1}^{N-m} s\left(f_{j}(\alpha, e)\right)$ decreases constantly because of relative depopulation and brain drain. Differentiating with respect to time and simplifying:

\footnotetext{
${ }^{19}$ We will come back to this issue later, when describing the qualitative effect of migration.
} 
$\Delta m=\frac{\left(m_{t-1}-m_{t-2}\right) R}{\Delta I_{m d}}+\frac{\sum_{j=1}^{N_{t-1}-m_{t-1}-m_{t}} s\left(f_{j}\left(\alpha_{j}, e_{j}\right)\right)-\sum_{j=1}^{N_{t-1}-m_{t-1}} s\left(f_{j}\left(\alpha_{j}, e_{j}\right)\right)}{\Delta I_{m d}}-\frac{\Delta C}{\Delta I_{m d}}$

Holding consumption and remittances constant, the growth in the migration rate is increasing in the number of compatriots abroad (if $\Delta I_{m d}$ is decreasing in the stock of compatriots), while component $\sum_{j=1}^{N_{t-1}-m_{t-1}-m_{t}} s\left(f_{j}(\alpha, e)\right)-\sum_{j=1}^{N_{t-1}-m_{t-1}} s\left(f_{j}(\alpha, e)\right)$ enters the equation with a negative sign. While depopulation is not observed at aggregate level, ${ }^{20}$ the decreasing quality of potential migrants must be taken into consideration. In the long term and in the absence of shocks reduced social contribution may have a negative influence on the council's budget. To avoid this risk, remittances must not be only higher than the cost of migration, but they must compensate for the loss of social contributions:

$$
R_{j}>s f_{j}\left(\alpha_{j}, e_{j}\right)+I_{m d}
$$

This condition ensures that financing migration is always profitable. This assumption is plausible and does not substantially modify the result of the model, except for the fact that it avoids complex relations between migration and council strategy.

Since depopulation is not an observed phenomenon in sending countries, it is necessary to define a rule of substitution of the leaving population. Independently of demographic dynamics, we assume that all migrants are replaced by applying one of the following rules: perfect replacement, random replacement with fixed distribution, random replacement with modified distribution.

Perfect replacement: whenever a New Adult $(i)$ migrates, that person is replaced in the origin country by another Adult $(j)$, equally able $\left(\alpha_{i}=\alpha_{j}\right)$ and skilled $\left(e_{i}=e_{j}\right)$.

Random replacement with fixed distribution (RRFD): whenever a New Adult migrates at time $t$, that person is replaced in the origin country by another Adult randomly drawn from the original distribution of ability and education.

Random replacement with modified distribution (RRMD): whenever a New Adult migrates at time $t$, that person is replaced in the origin country by another Adult randomly drawn from the distribution of ability and education at time $t$.

\footnotetext{
${ }^{20}$ Section 5 discusses what happens in the case of population growth.
} 
We begin our analysis with the simple case of perfect replacement.

Proposition 1: Under the hypotheses that:

- migrants are perfectly replaced;

- there is growth in outmigration between subsequent periods $\left(m_{t}>m_{t-1}\right)$;

- the economic distance between countries is not reduced $\left(z_{t} \geq z_{t-1}\right)$;

- costs and remittances are constant.

There is a negative cohort effect.

With perfect replacement, $p_{t}(\alpha, e)=p_{t-1}(\alpha, e), p_{t}(\alpha, e)$ being the distribution of $(\alpha, e)$ at time $t$. The number of migrants at time $t$ is:

$$
m_{t}=N \int_{\{f(\alpha, e)>\bar{f}\}} p_{t}(\alpha, e) \chi_{\left\{(\mathrm{z}-1) \mathrm{f}(\alpha, \mathrm{e})-\rho\left(\mathrm{I}_{\mathrm{md}}\right)-\mathrm{I}_{\mathrm{ma}}(\alpha)>0\right\}}(\alpha, e) d \alpha d e
$$

where $N$ is the total population, $\chi_{\left\{(\mathrm{z}-1) \mathrm{f}(\alpha, \mathrm{e})-\rho\left(\mathrm{I}_{\mathrm{md}}\right)-\mathrm{I}_{\mathrm{ma}}(\alpha)>0\right\}}$ the characteristic function which is 1 if a subject has the incentive to migrate and 0 otherwise. $p_{t}(\alpha, e)$ is the distribution of $(\alpha, e)$, and is the maximum value of $f(\alpha, e)$, such that all the population with $f(\alpha, e) \leq \bar{f}$ is not financed to migrate.

The above equation determines implicitly that $\bar{f}=\bar{f}\left(m_{t}\right)$ is a strictly decreasing function of $m_{t}$. This follows from the positivity of $p_{t}(\alpha, e)$, implying that the integrand in the above expression is positive; therefore the difference $m_{t-1}-m_{t}>0$ is positive if and only if condition $\bar{f}\left(m_{t}\right) \geq f(\alpha, e) \geq \bar{f}\left(m_{t+1}\right)$ is verified for some values of $(\alpha, e)$ - that is, if $\bar{f}\left(m_{t}\right)>\bar{f}\left(m_{t+1}\right)$.

As $f(\alpha, e)$ is an increasing function of $(\alpha, e)$, this implies that the flow of migrants at time $t+1$ is increased with respect to the flow at time $t$, but the difference between the two flows is composed of people with lower values of $(\alpha, e)$ compared with their migrant ancestors. That is, there is negative cohort effect.

To obtain analytical results about the effects of migration, we develop our analysis in the continuum. This is a good approximation for large populations and over long periods of time. This approximation is also a correct approach if subjects migrate at random times in a time continuum, which seems to be the case for migration. Obviously, continuum analysis does not allow us to evaluate the time-scale of migration. As a further technical simplification, migration and 
substitution occur at the same time. This is implicit in the continuum approximation and affects the general results only marginally.

Proposition 2: Under the hypotheses that:

- migrants are randomly replaced with fixed distribution or randomly replaced with modified distribution;

- economic distance between countries, costs and remittances are constant;

- the distribution of $f(\alpha, e)$ does not change during generational changes.

Both a negative cohort effect and brain drain occur. In addition, the quality of present migration is a function of past migration.

To prove proposition 2 and analyse its qualitative implications, some graphic representations are useful. Picture 1 shows a generic distribution of compound $(\alpha, e)$.

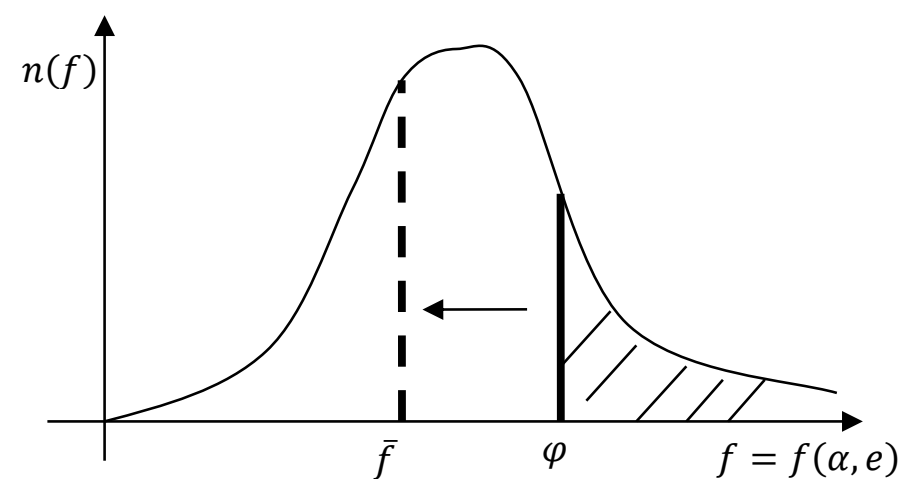

Picture 1 generic distribution of compound $(\alpha, e)$.

First, let us define $\bar{f}$ as the minimum level of compound $f(\alpha, e)$ at time $t$ for which there is an incentive to migrate. $\bar{f}$ is what we define to be the natural limit of migration: that is, the limit of the compound distribution at which there is no incentive to migrate at individual or community level:

$$
\bar{f} \equiv \max \left(\bar{f}_{\text {individual }}, \bar{f}_{\text {community }}\right)=\bar{f}\left(z, R\left(I_{m d}\right), I_{m a}\right)
$$

Define $n(f)$ as the number of people with $f(\alpha, e)=f$. The total population at the initial time is:

$$
N=\int_{0}^{\infty} n\left(f^{\prime}\right) d f^{\prime}
$$


$C(f)$ is the population with a level of ability $f(\alpha, e)<f$, and $H(f)$ is the population with $f(\alpha, e)>f:$

$$
C(f)=\int_{0}^{f} n\left(f^{\prime}\right) d f^{\prime}, \quad \text { and } \quad H(f)=N-C(f)
$$

Proof of Proposition 2. Define $h(t)$ to be the number of subjects in the population with $f(\alpha, e)>\varphi$. In the case of RRFD, we can write the continuous differential equation for $h(t)$ as:

$$
h(t+d t)=h(t)-m(t) d t+m(t) \frac{h(0)}{N} d t
$$

where $m(t)$ is the number of migrants at time $t$ and $m(t) \frac{h(0)}{N} d t$ the replacement term, when subjects are drawn from the original distribution of qualities. Thus:

$$
\begin{aligned}
& \frac{d h(t)}{d t}=-m(t)\left(1-\frac{h(0)}{N}\right) \\
& h(t)=h(0)-\int_{0}^{t} m\left(t^{\prime}\right) d t^{\prime}\left(1-\frac{h(0)}{N}\right)
\end{aligned}
$$

We can calculate the time at which condition $h(t)=0$ is attained as:

$$
h\left(t_{\varphi}\right)=0 \Leftrightarrow \frac{h(0)}{1-\frac{h(0)}{N}}=M\left(t_{\varphi}\right)
$$

where $M(t) \equiv \int_{0}^{t} m\left(t^{\prime}\right) d t^{\prime}$. At time $t_{\varphi}$ the population with $f(\alpha, e)=\varphi$ or higher has disappeared. Similarly, in the case of RRMD, we can write the continuous differential equation for $h(t)$ as:

$$
h(t+d t)=h(t)-m(t) d t+m(t) \frac{h(t)}{N} d t
$$

where $m(t)$ is the number of migrants at time $t$ and $m(t) \frac{h(t)}{N} d t$ the replacement term, when subjects are drawn from the compound distribution of qualities at the time migrants leave. Thus:

$$
\begin{aligned}
& \frac{d h(t)}{d t}=-m(t)\left(1-\frac{h(t)}{N}\right) \\
& \int_{h(0)}^{h(t)} \frac{d h}{1-\frac{h}{N}}=-\int_{0}^{t} m\left(t^{\prime}\right) d t^{\prime}
\end{aligned}
$$




$$
\begin{aligned}
& -N \ln \left(\frac{1-\frac{h(t)}{N}}{1-\frac{h(0)}{N}}\right)=-M(t) \\
& h\left(t_{\varphi}\right)=0 \Leftrightarrow-\ln \left(1-\frac{h(0)}{N}\right)=M\left(t_{\varphi}\right)
\end{aligned}
$$

Now we can replace $h(0)$ with initial cumulative function $H(\varphi(t))$, where $\varphi(t)$ is the maximum value of quality at time $t$ :

$$
\varphi(t)=\sup _{p_{t}(\alpha, e)} f(\alpha, e)
$$

The RRFD and RRMD migration equations are respectively:

$$
\frac{H(\varphi(t))}{1-\frac{H(\varphi(t))}{N}}=\int_{0}^{t} m\left(t^{\prime}\right) d t^{\prime} \equiv M(t), \quad \text { and }-N \ln \left(1-\frac{H(\varphi(t))}{N}\right)=M(t)
$$

where $M(t)$ is the total number of migrants from 0 to $t$. This means that migration is a cumulative phenomenon. The result validates the use of the migration propensity as proposed in Massey et al. (1994), and constitutes a theoretical basis for cumulative causation theory. As the above authors argue, characteristics of migration flows do not describe "the migration flow per se, but rather, a phase in its development". If we rewrite the two equation in terms of $H(\varphi(t))$, we can compute migrants' quality level:

$$
H(\varphi(t))=\frac{M(t)}{1+\frac{M(t)}{N}}, \quad \text { and } \quad H(\varphi(t))=N\left(1-e^{-\frac{M(t)}{N}}\right)
$$

That is, the quality of today's migrants is a function of the "community history of migration". We assume for example that a fixed number of migrants is sent abroad each round, that is, in each round the population with $f>\varphi(t)$ migrates. $\varphi(t)$ is a function of the incentives and strategies adopted by the Council. Under both replacement rules, in each round we observe a deterioration in the population quality level in terms of Education. Therefore, we observe brain drain and a negative cohort effect. In fact, $\varphi(t)$ decreases over time or, better, as $M(t)$ grows (graphically, $\varphi$ moves left each period). $H(\varphi(t))$ may be interpreted as the distribution of 
qualities which is "no longer present" ${ }^{21}$ with respect to the original distribution. $H(\varphi(t))=N-$ $C(\varphi(t))$ is the upper part of the original distribution ${ }^{22}$ and $C(\varphi(t))$ decreases as $\varphi(t)$ decreases.

Let us suppose that the council finances the same number of migrants each year. To keep this number constant each round, the Council must move the minimum level of required abilities to the left. This reduces the quality of those not involved in migration and, given the structure of our economy, the quality of their offspring. The quality of offspring, i.e., their education, is a function of the parents' current investment in education, that is, a function of their income. As income increases in innate abilities (which are independent among generations) and in education (which is correlated among generations), and as those who leave are on average better educated, they are the richer ones. Those who remain have lower incomes, and thus less possibility of investing in the education of offspring, and so on.

With each "step" in the migration we observe a brain-drain in the sending country and a negative cohort effect in the receiving: as the quality of those who remain decreases, so does the quality of migrants. In particular, what decreases is their average education that is usually the only observable characteristics.

These two consequences of migration flows can be observed without exception when applying RRFD and RRMD, or a mixed replacement rule. The main difference between the two forms of replacement is the speed of convergence to the natural limit of migration. In both cases, there exist a limit to the process just described. The limit is fixed at the level at which:

$$
H(\varphi(t))=H(\vec{f})
$$

In both cases, $\lim _{\frac{M(t)}{N} \gg 1} H(\varphi(t))=H(\bar{f})$, where $\bar{f}$ is a function of: the level of physical and psychological costs, the expected returns, and the remittance level. Although a different rule of replacement implies a different speed in reaching this limit (slower under RRFD and faster under RRMD), we identify three main scenarios (see Pictures 2, 3 and 4) under the vinculum of constant migration flows. ${ }^{23}$

\footnotetext{
${ }^{21}$ All people belonging to that part of the distribution migrate.

${ }^{22}$ The shaded area in Picture 1.

${ }^{23}$ Increasing migration flows will only speed up the process, thus further emphasizing our results. What happens under decreasing migration flows needs deeper investigation.
} 


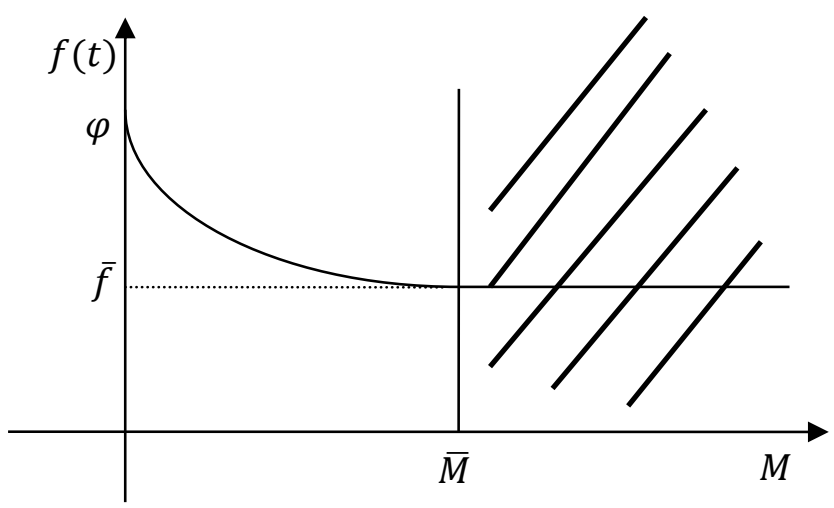

Picture 2: Natural limit of migration

Picture 2 shows the normal case. The quality of migrants sent each period decreases as $M$ grows. When level $\bar{M}$ is reached ${ }^{24}$ no further decrease in migrants' quality is observed: we may say that migration ceases. This does not mean that no migration can be observed, but that, by chance, once someone appears in the sending country's economy with an ability level higher than $\bar{f}$, that person is "instantaneously" financed to migrate. In the long term we may say that migration ceases, because almost nobody has the incentive to migrate.

Picture 3 shows a scenario in which the economic distance between the two countries is so large and/or costs are so low that migration never stops. That is, $\varphi$ is always higher than $\bar{f}$. For example, the receiving country may be psychologically attractive (the psychological cost of migration is zero or less) and, for some reason, migration costs are especially low (common language, border sharing). In this situation, $\varphi$ decreases step by step until each member of the sending country has migrated. ${ }^{25}$

\footnotetext{
${ }^{24}$ In principle, this value may be identified if we knows details of the original population: original distribution of $(\alpha, e)$, and the cost of migration. Value $\bar{M}$ also identifies a unique period $t$ of time (in the absence of shocks).

${ }^{25}$ This is the case of countries migrants are obliged to cross to reach their preferred destination. In some of these countries migrants may stay longer than just the time to cross them, for example, because they need to accumulate capital to finance the remaining migration. These countries observe a continuum of migrants leaving to reach their preferred destination psychologically attractive and entering (replacing those who leave). We do not observe depopulation because the transitory flow continues in the long term.
} 


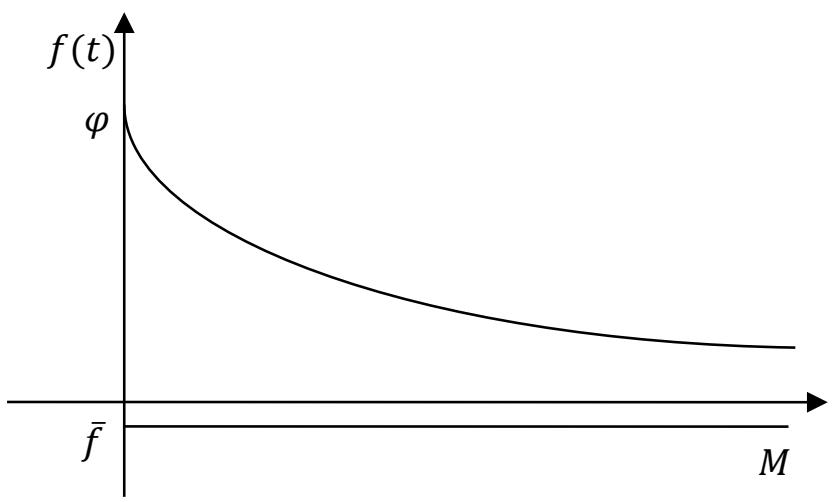

Picture 3: Migration "without Natural Limit"

Picture 3 shows the extreme case, in which $\bar{f}$ is negative. This is not necessarily the only representation for migration without natural limit. It may simply be that the lowest level of $\varphi$ is always larger than $\bar{f}$. This is possible if there exists a minimum of the distribution of $(\alpha, e)$ that is larger than $\bar{f}$.

Picture 4 displays the case in which initial costs make migration non-profitable, and, so no migration is observed.

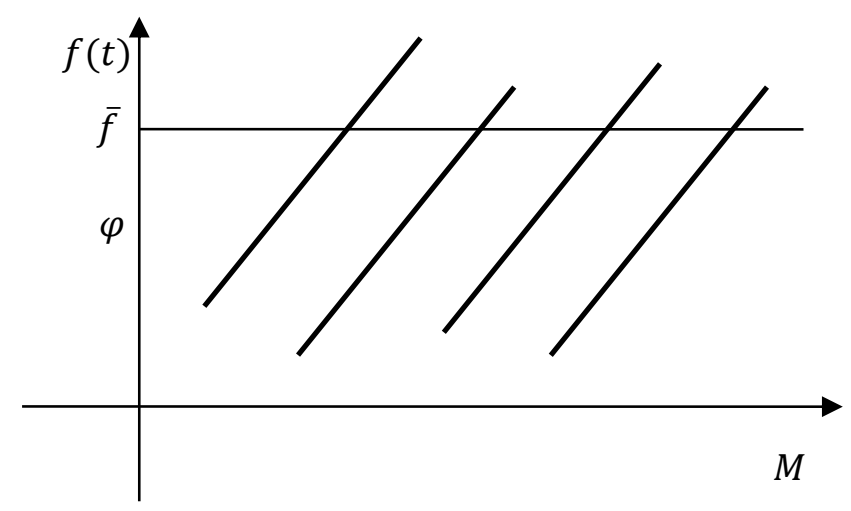

Picture 4: No Migration

These findings are robust even when a mix replacement rule is applied. Let us assume that both the total population and outmigration are constant, and define $r_{0}$ and $r_{1}$ as the percentage of migrants who are substituted by applying RRFD and RRMD, respectively, $\left(1-r_{0}-r_{1}\right)$ is the percentage of migrants replaced with identical subjects.

Proposition 3: independently of the replacement rule adopted, in the condition of: 
- no full perfect substitution (i.e. $0<r_{0}+r_{1} \leq 1$ );

- constant population;

- no changes in the fundamentals of both economies;

brain drain and a negative cohort effect are the results of migration flows.

Defining $M(t)$ as the total number of migrants:

$$
M(t)=\frac{N(t)}{r_{1}} \ln \left[\frac{r_{0}\left(\frac{H(\varphi(t))}{N(0)}-1\right)-r_{1}}{r_{0}\left(\frac{H(\varphi(t))}{N(0)}-1\right)+r_{1}\left(\frac{H(\varphi(t))}{N(0)}-1\right)}\right]
$$

The equation is a weighted form of the migration equation in the case of RRMD, and therefore has the same dynamics concerning migration flows and the quality of migrants.

Before moving to the analysis of migrant networks and their effect on migration paths, let us summarize the main results of this section. We show that, in a simple overlapping generation economy, in which only ability and education determine the wellbeing of households, several phenomena can be observed when introducing migration.

We prove that migration over time modifies the structure of the economy. Each migrant is affected and affects other people's migration choices. This self-perpetuating phenomenon has a limit in terms of numbers of migrants and their ability levels: the natural limit of migration.

We also prove that, in some specific conditions, particularly in positive self-selection, a negative cohort effect and brain drain are the normal consequences of migration. This result has great importance for two main reasons. First of all, it explains the contrasting results obtained by scholars when analyzing the level of selection of migrants, reconciling positive selectivity with a negative cohort without introducing new variables. In particular, the negative cohort effect is not the effect of decreasing selectivity and does not requires a reduction in costs (allowing newcomers from lower levels of the education/income distribution), but is the result of the increased possibility that sending communities have of financing migration, and of the brain drain which decreases the quality of potential migrants. 


\section{Effect of Migrant Networks}

Migrant networks are usually identified as the main cause of the negative cohort effect. In our framework it is not necessary to reduce migration costs in order to observe the negative cohort effect. Therefore, the role of networks must be examined to understand their influence on the dynamics of the model.

Reduction in costs and risks due to networks may be implemented in our model through the incentive mechanism at individual and community levels. The individual incentive is:

$$
\begin{aligned}
& (z-1) f(\alpha, e)-R-I_{m a}(\alpha) \geq 0 \\
& \text { or }(z-1) f(\alpha, e)-\rho\left(I_{m d}\right)-I_{m a}(\alpha) \geq 0
\end{aligned}
$$

where $\rho($.$) is the remittance mark-up function determined by the Council of Elders. The$ community level incentive is:

$$
R_{j}>s f_{j}\left(\alpha_{j}, e_{j}\right)+I_{m d}
$$

That is, the return of the investment in migration must be larger than the cost and loss of social contributions. We also know that incentives enter the model through the natural limit of migration. We define the natural limit of migration as the value of compound $(\alpha, e)$ at which migration is no longer attractive. Recalling that:

$$
\bar{f} \equiv \max \left(\bar{f}_{\text {individual }}, \bar{f}_{\text {community }}\right)=\bar{f}\left(z, R\left(I_{m d}\right), I_{m a}\right)
$$

If networks are able to modify costs and risks and thus the expected return of migration, we can rewrite the migration incentive equations:

$$
\begin{aligned}
& (z(M)-1) f(\alpha, e)-\rho\left(I_{m d}(M)\right)-I_{m a}(\alpha, M) \geq 0, \\
& \text { and } \quad R_{j}>s f_{j}\left(\alpha_{j}, e_{j}\right)+I_{m d}(R)(44 a \& b)
\end{aligned}
$$

Hence for $\bar{f}=g\left(z(M), R\left(I_{m d}(M)\right), I_{m a}(M)\right)$. Thus if $M \uparrow \Rightarrow \bar{f}(M) \downarrow$.

We identify some peculiar scenarios (see Picture $5-9$ ). We must define $M_{0}$ and $\bar{M}$ before describing each scenario.

$M_{0}$ is the minimum value of $M$ such that $M: 0 \leq M<M_{0} \Rightarrow \varphi(M)<\bar{f}(M)$ 
$\bar{M}$ is the maximum value of $M$ such that $\forall M: M_{0}<M<\bar{M} \Rightarrow \varphi(M)>\bar{f}(M)$

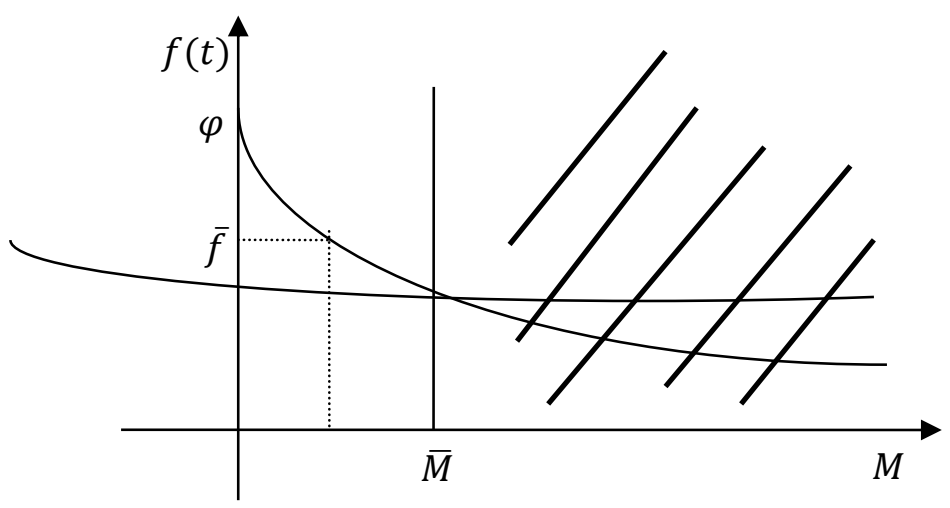

Picture 5: Natural level of migration decreasing as $\mathrm{M}$ grows.

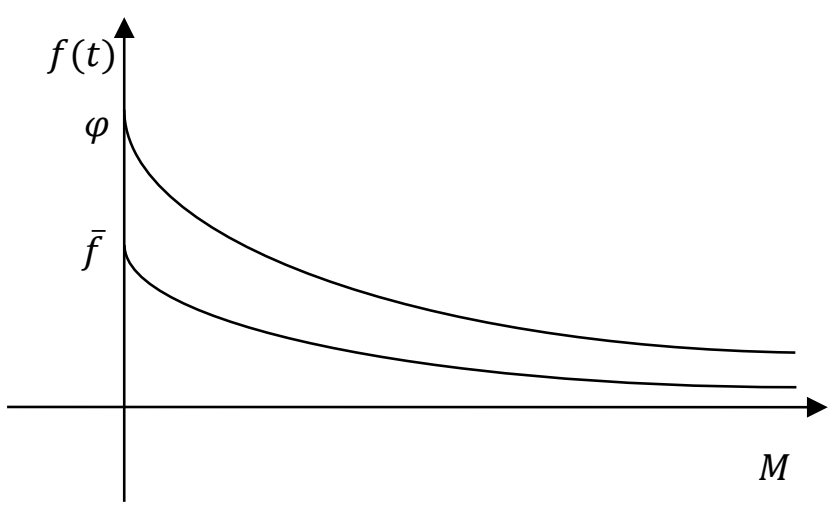

Picture 6: Strong Network Effect

Pictures 5 and 6 respectively show the evolution of the scenarios of Pictures 2 and 3 . In Picture 5, the scenario satisfies the following condition:

$$
\varphi(0)>\bar{f}(0), \text { and } \varphi(+\infty)<\bar{f}(+\infty)
$$

This is the typical effect of networks hypothesized in the literature. At the beginning ( $t$ and $M$ close to 0 ), costs of migration are high, so only those with higher levels of abilities and education have an incentive to migrate. ${ }^{26}$ Once migration starts, the presence of compatriots reduces the cost and risk of less skilled compatriots. Networks speed up migration and reduce the natural level of migration $(\bar{f})$, increasing the total amount of potential migrants. The new endpoint

\footnotetext{
${ }^{26}$ Moreover, the more skilled are usually people belonging to wealthier social groups who can afford higher migration costs.
} 
has a higher value of $\bar{M}$ and a lower level of qualification of migrants with respect to a situation in which networks have no effect on costs and risks.

As Picture 6 shows the brain drain effect may be slower than the speed at which networks reduce costs and risks (i.e., $\varphi(M)>\bar{f}(M) \forall M \geq 0$ ). This means that migration will never cease (at the limit, we see everyone migrating, even those who have a compound of ability and education close to 0$)$.

Picture 7 shows the opposite scenario. While at the beginning, as a rule, networks reduce the costs and risks of migration, increasing migration flows (or, rather, the number of subjects who have an incentive to migrate), they produce the opposite effect when a certain critical mass is reached. This may happen, for example, when networks become "ghettos".

There are economic explanations for the U-shaped form shown in Picture 7. As we have seen, $\bar{f}(M)$ is determined by migration costs and economic distance between countries. If both psychological and physical costs decrease as the network grows, the relationship between $z$ and $M$ is a priori unclear. On one hand $z$ should increase in $M$. Networks increase the probability of getting a job in the receiving country, increasing the expected return of migration. Nonetheless, the informative advantage has an upper bound as $M$ grows. On the other hand, being migrants usually concentrated in some regions and economic sectors, large migration flows produce an excess of labor supply, increasing unemployment and thus reducing the economic distance between countries. ${ }^{27}$

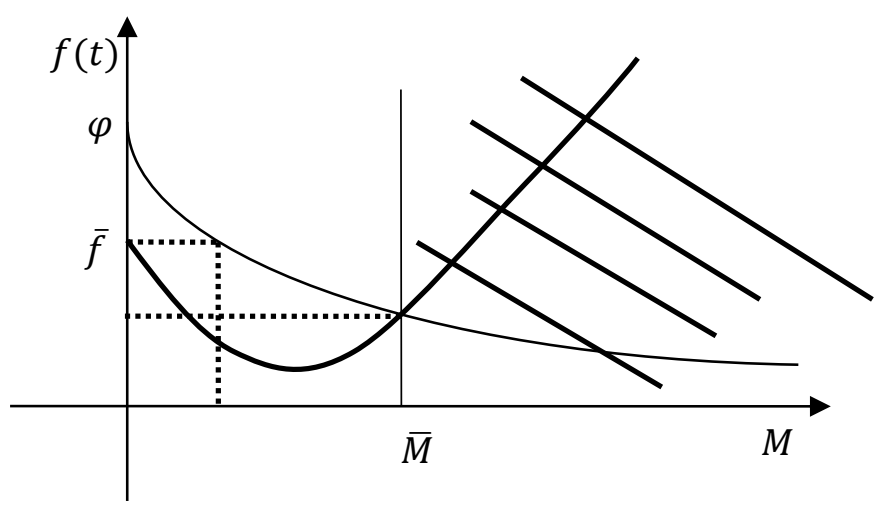

Picture 7: U-Shaped network effect

\footnotetext{
${ }^{27}$ We may also observe salary growth in sending countries, because of the relative scarcity of workers.
} 
Pictures 8 and 9 shows two scenarios in which migration cannot start spontaneously. The costs of migration are too high, and so nobody has an incentive to migrate. If something breaks the equilibrium ${ }^{28}$ and threshold $M_{0}$ is reached, the self-perpetuating process described previously can start. In Picture 9, $\bar{f}$ and $\varphi$ cross twice, and there is nothing which excludes the possibility that there are many more different crossing-points.

One scenario that may generate multiple crossing-points is when migrants move from one economic sector or region to another. Such intra-sector movements happen whenever the saturation point of one sector is reached. If migrants concentrate in a particular economic sector (in Europe, it may be the construction industry, in the US the agricultural sector) the result is an excess of supply. Because the network and its members are specialized in that particular work sector, ${ }^{29}$ it will take time to get successful results in other economic areas. Once the door of a new sector is opened, the network comes back to its self-increasing function.

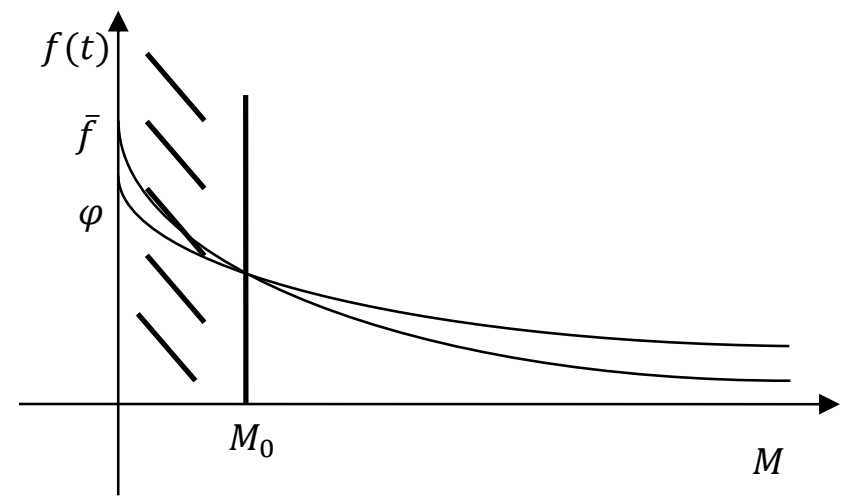

Picture 8: Threshold

\footnotetext{
${ }^{28}$ We have several historical examples of this scenario: the colonization of Australia with convicts, deportation because of civil war, the creation of a state like Israel, and family reunification after the Second World War and the Vietnam war.

${ }^{29}$ They have specific skills, contacts and information on available job positions in the sector, and even monopolistic positions in the job market of the sector.
} 


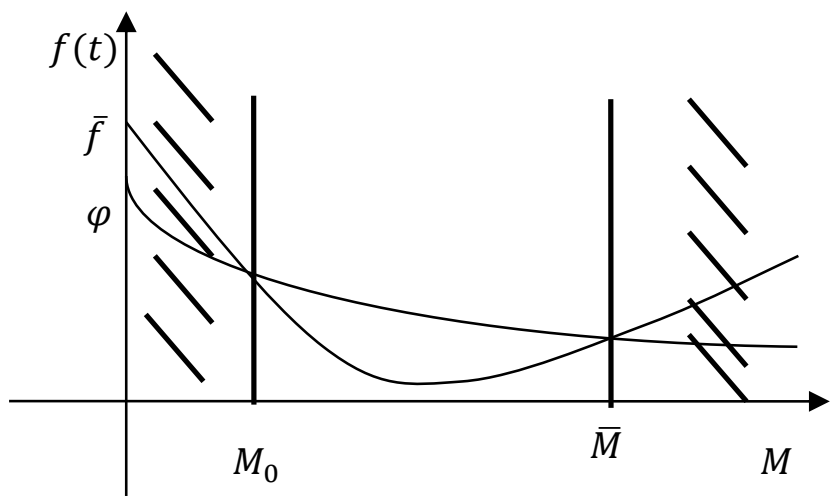

Picture 9: Threshold and ghetto

All scenarios identified above may be synthesized in a single theorem.

Assumption A: $\bar{f}(M)$ is a continuous function of the network size $M$. The effect of the network on $\bar{f}(M)$ (i.e. $\bar{f}(M)-\bar{f}(0)$ ) is always negative or zero for $M>0 .{ }^{30}$ Define

$$
M_{0}=\inf \left\{M \in R_{0}^{+} \mid \varphi(M)>\bar{f}(M)\right\}
$$

and

$$
M_{\infty}=\sup \left\{M \in R_{0}^{+} \mid \varphi(M) \geq \bar{f}(M) \text { et } \nexists M^{\prime} \in R^{+}, M_{0}<M^{\prime}<M \text { s.t. } \varphi\left(M^{\prime}\right) \leq \bar{f}\left(M^{\prime}\right)\right\}
$$

$M_{0}$ represents the lower threshold for migration and $M_{\infty}$ the upper limit of migration. Both $M_{0}$ and $M_{\infty}$ can be in either $R_{0}^{+}$or $+\infty$.

Lemma 1: if a value $M$ exists such that $\varphi(M)>\bar{f}(M)$, then $M_{0} \leq M_{\infty}$, otherwise $M_{0}=+\infty$ and $M_{\infty}=0$.

Proof: if $\mathrm{M}_{0} \in \mathrm{R}_{0}^{+}$, then $\varphi\left(\mathrm{M}_{0}\right)=\overline{\mathrm{f}}\left(\mathrm{M}_{0}\right)$, and it therefore belongs to the set:

$$
\mathrm{M}_{\infty}=\sup \left\{\mathrm{M} \in \mathrm{R}_{0}^{+} \mid \varphi(\mathrm{M}) \geq \overline{\mathrm{f}}(\mathrm{M}) \text { et } \nexists \mathrm{M}^{\prime} \in \mathrm{R}^{+}, \mathrm{M}_{0}<\mathrm{M}^{\prime}<M \text { s.t. } \varphi\left(\mathrm{M}^{\prime}\right) \leq \overline{\mathrm{f}}\left(\mathrm{M}^{\prime}\right)\right\}
$$

Therefore, the supremum of this set is greater than or equal to $M_{0}$, i.e., $M_{0} \leq M_{\infty}$.

Theorem 2: in the absence of a network, $M_{0}$ may be either 0 or $+\infty$, and there exist only three possible scenarios:

\footnotetext{
${ }^{30}$ This assumption is explained by noting that for $M=0$ the network is absent and cannot affect $\bar{f}$. In addition, if the effect of the network on $\bar{f}$ becomes positive for $M>0$, then it is always possible to migrate outside the network or to other areas. Thus, the actual effect of the network is null. This assumption implicitly does not account for racism and ghetto phenomena which affect migrants independently of their position with respect to the network.
} 
- (a1) $M_{0}=+\infty$ et $M_{\infty}=0$ : no migration;

- (b1) $M_{0}=0$ et $M_{\infty} \in R^{+}$: limited migration;

- (b2) $M_{0}=0$ et $M_{\infty}=+\infty$ : unlimited migration.

When a network is present, then $M_{0}^{(\text {network })} \leq M_{0}^{(\text {no network })}$ and $M_{\infty}^{(\text {network })} \leq M_{\infty}^{(\text {no network })}$ (that is, the existence of a network always increases the possibility of migrating) and five possible scenarios exist:

- (a1') $M_{0}=+\infty$ et $M_{\infty}=0$ : no migration (corresponding to (a1) in the absence of a network);

- (a2') $M_{0}=M_{\infty} \in R^{+}$: a pathological case, with migration above multiple (infinite) thresholds (corresponding to (a1) in the absence of a network);

- (a3') $M_{0} \in R^{+}$et $M_{\infty} \in R^{+}$et $M_{0}<M_{\infty}$ : limited migration above the threshold (corresponding to (a1) in the absence of a network);

- (a4') $M_{0} \in R^{+}$et $M_{\infty}=+\infty$ : unlimited migration above the threshold (corresponding to (a1) in the absence of a network);

- (b1') $M_{0}=0$ et $M_{\infty} \in R^{+}$: limited migration (corresponding to (b1) in the absence of a network);

- (b2') $M_{0}=0$ et $M_{\infty}=+\infty$ : unlimited migration (corresponding to (b1) or (b2) in the absence of a network).

Proof: without a network, $\varphi(M)-\bar{f}$ is a continuous and strictly decreasing function of $M$, so that the set $\left\{M \in R_{0}^{+} \mid \varphi(M)>\bar{f}(M)\right\}$ corresponds either to the interval $\left[0, M_{\infty}\right)$ or to the empty set, so that $M_{0}=0$ or $M_{0}=+\infty$.

From the assumption on the effect of networks: $\bar{f}(M) \leq \bar{f}(0)$ therefore the set $\left\{M \in R_{0}^{+} \mid \varphi(M)>\right.$ $\bar{f}(0)\}$ is a subset of $\left\{M \in R_{0}^{+} \mid \varphi(M)>\bar{f}(M)\right\}$. From the properties of the infima we obtain:

$$
M_{0}^{(\text {network })} \leq M_{0}^{(\text {no network) }}
$$

Similarly, $M_{\infty}^{(\text {network })} \leq M_{\infty}^{(\text {no network })}$ can be verified by studying the two cases $M_{0}^{(\text {no network) }}=0$ and $M_{0}^{(\text {no network) }}=+\infty$ separately. If $M_{0}^{(\text {no network) }}=+\infty$ then $M_{\infty}^{(\text {no network })}=0 \leq M_{\infty}^{(\text {network })}$, because it is the supremum of an empty set. If $M_{0}^{(\text {no network) }}=0$, the set $\left\{M \in R_{0}^{+} \mid \varphi(M) \geq \bar{f}(0)\right\}$ is a subset of $\left\{M \in R_{0}^{+} \mid \varphi(M) \geq \bar{f}(M)\right\}$, and set $\left\{\mathrm{M} \in \mathrm{R}_{0}^{+} \mid \nexists \mathrm{M}^{\prime} \in \mathrm{R}^{+}, \mathrm{M}^{\prime}<M\right.$ s.t. $\left.\varphi\left(\mathrm{M}^{\prime}\right) \leq \overline{\mathrm{f}}(0)\right\}$ is 
a subset of $\left\{\mathrm{M} \in \mathrm{R}_{0}^{+} \mid \nexists \mathrm{M}^{\prime} \in \mathrm{R}^{+}, \mathrm{M}^{\prime}<M\right.$ s.t. $\left.\varphi\left(\mathrm{M}^{\prime}\right) \leq \overline{\mathrm{f}}\left(\mathrm{M}^{\prime}\right)\right\}$. Therefore, we can obtain $M_{\infty}^{(\text {network })} \geq M_{\infty}^{(\text {no network })}$ from the properties of the suprema of the joint set. From these results and the constraints on $M_{0}$ and $M_{\infty}$ classification of the scenarios proposed in the theorem is straightforward.

\section{Population Growth}

In this section we examine what happens when we introduce population growth. To implement population growth, we assume that migrants keep the rates of population growth at home and in the receiving country constant. ${ }^{31}$ To simplify the analysis, we derive the model under the FFMD substitution method.

We rewrite the equations, such that $H(\varphi(t))$ is the number of Adults with value of compound $(\alpha, e)$ larger than $\varphi(t)$ in the initial distribution. $\varphi(t)$ is the upper limit of the compound distribution in $t$ and is the minimum level of the compound to be financed at time $t$. Define $\frac{H(\varphi(t))}{N(0)}$ as the percentage of the initial population with compound value larger than $\varphi(t)$ :

$$
\frac{H(\varphi(t))}{N(0)}=\widehat{H}(\varphi(t))
$$

Because we assume that the fertility rate in sending and receiving countries does not vary, we define $M(t)$ as the number of migrants and all their offspring in the receiving country. That is:

$$
M(t)=\int_{0}^{\tau} m(\tau) \frac{N(t)}{N(\tau)} d \tau
$$

where $m(\tau)$ is the number of migrants at $\tau$. If we assume that $\bar{f}$, as in the previous Section, is a function of the total network of migrants (including offspring), thus:

$$
\bar{f}=f(M(t))
$$

\footnotetext{
${ }^{31}$ This assumption is plausible for first-generation migrants, but becomes problematic when we consider second- and third-generation migrants, who usually standardize to the rate of reproduction of the receiving country.
} 
This implies that:

$$
\frac{M(t)}{N(t)}=G(\widehat{H}(\varphi(t)))
$$

where $G()=.-\ln (1-x)$ is an increasing function in $0<x<1$. To investigate the dynamics, we need to fix the population at a certain positive value. We can write:

$$
\varphi(t)=\widehat{H}^{-1}\left(G^{-1}\left(\frac{M(t)}{N(t)}\right)\right)
$$

Where $\varphi(t)$ is decreases in $M(t)$ and increases in $N(t)$. Picture 10 shows this scenario. The main difference with respect to the previous scenario is that, here, $\varphi(t)$ is a family of curves which vary as $N(t)$ varies. The family of curves is also constituted by the same curve rescaled on the horizontal axis with a scale factor proportional to $N$.

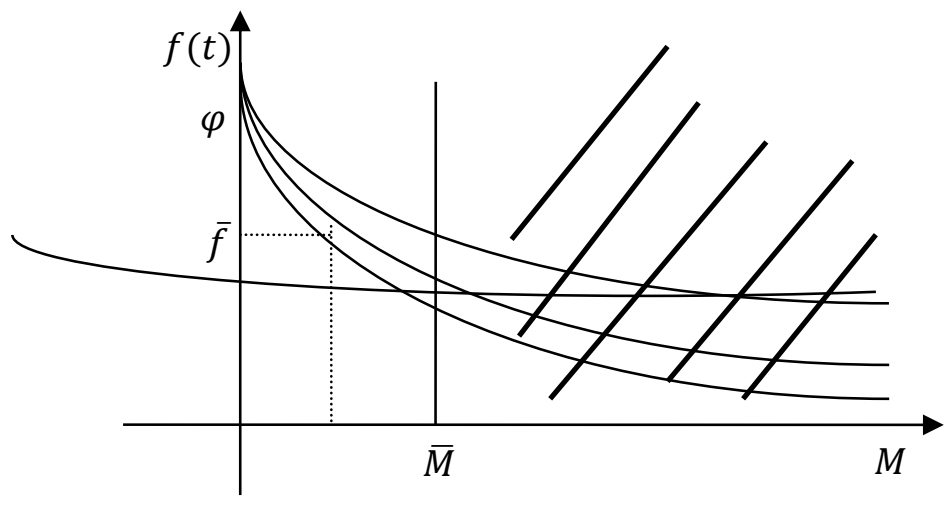

Picture 10: Population Growth

\section{Conclusions}

The theoretical analysis presented here, giving a formal representation to Cumulative Causation approach, brings together several lines of thought on the relation between migration, education and networks. We started from an overlapping generation model along the lines of Loury (1981) introducing a second market for workers. Once economic agents are allowed to migrate, properties identified by Loury are preserved.

This allowed us to study the dynamics of migration flows with a strong focus on the quality of migrants. Starting from the assumption that a single subject cannot, alone, finance migration (which seems to be the case for the largest groups of migrants), we introduced a "planner", which 
decides how many people and who can be financed. The planner, called the Council of Elders in the model (somehow inspired to the structure of Senegalese fraternal orders - Riccio: 2004), does not need to be structured at village (or higher) level, but may simply be a group of household heads taking decisions in an enlarged family network.

We agree with Chiswick (1978) that migrants are favorably selected, and show that decreasing quality among subsequent cohorts is not incompatible with this assumption. Once migration starts, independently of the method of substitution used (which is not-quality improving), two main forces reduce the observable quality of migrants: (1) when migration flows increase in dimension, from time to time there will be enough resources to finance less and less skilled people until the natural level of migration is reached; (2) given the intergenerational transmission of education and the independence of innate abilities, there will be a draining effect.

What is observed in the receiving country (where data are usually collected) is a decreasing level in the observable quality, and thus a negative cohort effect in terms of education. This effect can not only occur in the case of extremely positive self-selection, but it is its consequence when there are no investments to compensate for brain drain.

To the best of our knowledge, this is the first time that Cumulative Causation theory has been formalized and investigated in terms of quality of migrants, without the need to introduce networks. The cumulative process takes place even when networks are not present.

However, since migrant networks are crucial in migration we modeled the effect of networks in our simplified economy. As we showed, even when networks are not at the origin of the self-perpetuating mechanism, they can strongly influence the convergence path, speed of convergence, and endpoint values. In addition, by reducing the costs and risks of migration, networks can increase the negative cohort effect and also produce opposite results. In fact, congestion and excess of labor supply may reduce the incentive to migrate.

Our model is a simplified possible formalization to the Cumulative Causation theory of migration in which each migrant is influenced by those who migrated previously and in turn influences those who migrate later. Migration time (expressed as numbers of migrants) and the quality of migrants are two sides of the same coin and, once one of the two is known, we can predict the other. The framework allows us to predict the path a migration flow will take in the future and when its natural end will occur, in terms not only of numbers but also of qualities. 
In our model, the developmental strategy adopted by the Council of Elders plays a cardinal role in determining migration flows. To develop our analysis, we make only one assumption: a single strategy exists and even if it is not optimal, it is kept constant in time. Nonetheless, the ability to reinvest in the local economy instead of in consumption, to invest in education, and/or to adopt long term development strategies (if computable) all mitigate the negative effects of migration, and may also produce the reverse scenario. Promoting local economic growth, investing in children's education, and developing the right mix between investing in migration and in future generations, all produce a "virtuous" mechanism which, in principle, will reduce the gap between countries, therefore reducing migration flows and increasing the skill levels of new cohorts of migrants.

\section{References}

Borjas, George J. "Assimilation, Changes in Cohort Quality, and the Earnings of Immigrants.» Journal of Labor Economics 77, n. 4 (Oct. 1985): 463-89

Chiswick, Barry R. «Are Immigrants Favorably Self-Selected?» The American Economic Review (American Economic Association) 89, n. 2 (May 1999): 181-185

Chiswick, Barry R. "The Effect of Americanization on the Earnings of Foreign-born Men.» The Journal of Political Economy 86, n. 5 (Oct. 1978): 897-921.

Docquier, Frédéric, e Hillel Rapoport. «Remittances and Inequality: A Dynamic Migration Model.» IZA Discussion Papers (Institute for the Study of Labor (IZA)), n. 808 (2003).

Durand, Jorge, Douglas S. Massey, e Rene M. Zenteno. «Mexican Immigration to the United States: Continuities and Changes.» Latin American Research Review 36, n. 1 (2001): 107-127

Hanson, Gordon H., e Antonio Spilimebrgo. «Illegal Immigration, Border Enforcement, and Relative Wage: Evidence from Apprehensions at the U.S.-Mexico Border.» The American Economic Review 89, n. 5 (Dec. 1999): 1337-1357.

Loury, Glenn C. «Intergenerational Transfers and the Distribution of Earnings.» Econometrica 49, n. 4 (Jul. 1981).

Massey, Douglas S., Andrew B. Gross, e Kumiko Shibuya. «Migration, Segregation, and the Geographic Concentration of Poverty ." American Sociological Review 59, n. 3 (Jun. 1994): 425-445. 
Massey, Douglas S., Joaquin Arango, Graeme Hugo, Ali Kouaouci, Adela Pellegrino, e J. Edward Taylor. «Theories of International Migration: A Review and Appraisal.» Population and Development Review (Population Council) 19, n. 3 (September 1993): 433-466.

McKenzie, David, e Hillel Rapoport. «Network effects and the dynamics of migration and inequality: Theory and evidence from Mexico.» Journal of Development Economics 84 (2007): 1-24.

McKenzie, David, e Hillel Rapoport. «Self-Selection patterns in Mexico-U.S. migration: The role of migration networks.» World Bank Working Paper, 2007

McKenzie, David, e Hillel Rapoport. «Can migration reduce educational attainment? Evidence from Mexico.» World Bank Policy Research Working Paper, n. 3952 (June 2006).

B. Riccio, "Les migrants sénégalais en Italie. Le potentiel d'investissement du capital 25humain et financier pour la réduction de la pauvreté urbaine au Sénégal", Ministre du Patrimoine Bati, de l'Habitat et de la Construction, République du Sénégal, Dakar (2004)

Yang, Dean. «International Migration, Remittances and Household Investment: Evidence from Philippine Migrants' Exchange Rate Shocks.» The Economic Journal, n. 118 (April 2008): 591-630.

Zimmerman, Frederick J., e Michael R. Carter. «Asset smoothing, consumption smoothing and the reproduction of inequality under risk and subsistence constraints.» Journal of Development Economics 71 (2003): 233-260.

\section{Appendix A}

Following Loury (1981) we must show that mapping $T: C[0, \bar{y}] \rightarrow C[0, \bar{y}]$ is a contraction mapping thus has a unique fixed point. The map is defined by:

$$
(T \Phi)=\max _{0 \leq c \leq y} E_{\alpha} \widetilde{U}_{\alpha}(c, \Phi(f(\alpha, y-c)))(a)
$$

where $\widetilde{U}_{\alpha}= \begin{cases}\mathrm{U}\left(\mathrm{c}, \Phi\left(f\left(\alpha_{2}, \mathrm{e}\left(\mathrm{y}_{1}-\mathrm{c}\right)\right)\right)\right) & \text { if } 0 \leq \alpha_{2}<\bar{\alpha} \\ \mathrm{U}\left(\mathrm{c}, \mathrm{V}_{\mathrm{m}}^{*}\left(\mathrm{z} f\left(\alpha_{2}, \mathrm{e}\left(\mathrm{y}_{1}-\mathrm{c}\right)-\rho\left(\mathrm{I}_{\mathrm{md}}\right)-\mathrm{I}_{\mathrm{ma}}\left(\alpha_{2}\right)\right)\right)\right. & \text { if } \bar{\alpha} \leq \alpha_{2}<1\end{cases}$

for $\Phi \in C[0, \bar{y}]$ define $\|\Phi\|=\sup _{x \in[0, y]}|\Phi(x)|$. Under this norm $T$ is a contraction on $C[0, \bar{y}]$, thus, let $\Phi, \Psi \in C[0, \bar{y}]$ :

$$
\|T \Phi-T \Psi\| \equiv \sup _{\bar{y} \geq y \geq 0}\left|\max _{0 \leq c \leq y} E_{\alpha} \widetilde{U}_{\alpha}(c, \Phi(f(\alpha, y-c)))-\max _{0 \leq c \leq y} E_{\alpha} \widetilde{U}_{\alpha}(c, \Psi(f(\alpha, y-c)))\right|
$$


Let $\dot{c}(y)$ give the maximum for $E_{\alpha} \widetilde{U}_{\alpha}(c, \Phi)$ and $\ddot{c}(y)$ give the maximum for $E_{\alpha} \widetilde{U}_{\alpha}(c, \Psi)$, and defining $\tilde{E}_{\alpha} g(\alpha)=\int_{0}^{\bar{\alpha}} \mathrm{d} \alpha_{2} \mathrm{p}_{\alpha}\left(\alpha_{2}\right) g(\alpha)$, then:

$$
\begin{aligned}
& \|T \Phi-T \Psi\| \equiv \sup _{\bar{y} \geq y \geq 0}\left|E_{\alpha}\left(\widetilde{U}_{\alpha}(\dot{c}, \Phi)-\widetilde{U}_{\alpha}(\ddot{c}, \Psi)\right)\right| \\
& \leq \sup _{\bar{y} \geq y \geq 0} \max \left\{\left|E_{\alpha}\left(\widetilde{U}_{\alpha}(\dot{c}, \Phi)-\widetilde{U}_{\alpha}(\dot{c}, \Psi)\right)\right| ;\left|E_{\alpha}\left(\widetilde{U}_{\alpha}(\ddot{c}, \Phi)-\widetilde{U}_{\alpha}(\ddot{c}, \Psi)\right)\right|\right\} \\
& \leq \sup _{\bar{y} \geq y \geq 0} \max \left\{\left|\widetilde{E}_{\alpha}(U(\dot{c}, \Phi)-U(\dot{c}, \Psi))\right| ;\left|\widetilde{E}_{\alpha}(U(\ddot{c}, \Phi)-U(\ddot{c}, \Psi))\right|\right\} \\
& \leq \max \left\{\sup _{\bar{y} \geq y \geq 0}\left|\widetilde{E}_{\alpha}\left(U_{2}(\dot{c}, \Psi) \cdot[\Phi-\Psi]\right)\right| ; \sup _{\bar{y} \geq y \geq 0}\left|\widetilde{E}_{\alpha}\left(U_{2}(\ddot{c}, \Psi) \cdot[\Phi-\Psi]\right)\right|\right\} \\
& \leq \gamma \max \left\{\sup _{\bar{y} \geq y \geq 0}|\Phi(f(\alpha, y-\dot{c}(y)))-\Psi(f(\alpha, y-\dot{c}(y)))| ;\right. \\
& \left.\quad \sup _{\bar{y} \geq y \geq 0}|\Phi(f(\alpha, y-\ddot{c}(y)))-\Psi(f(\alpha, y-\ddot{c}(y)))|\right\} \alpha \in[0,1] \\
& \quad \leq \gamma \sup _{\bar{y} \geq y \geq 0}|\Phi(y)-\Psi(y)|=\gamma\|\Phi-\Psi\|
\end{aligned}
$$

for some $0<\gamma<1$, using assumption 3. Thus $T$ is a contraction and according to the Banach Fixed Point Theorem, there exist an unique fixed point $V^{*} \in C[0, \bar{y}]$ that is the solution to (a). 


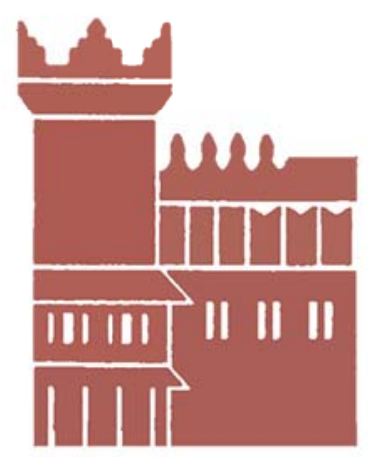

Alma Mater Studiorum - Università di Bologna DEPARTMENT OF ECONOMICS

Strada Maggiore 45

40125 Bologna - Italy

Tel. +39051 2092604

Fax +390512092664

http://www.dse.unibo.it 